\title{
SUPEREXPLOTACIÓN DE LA NATURALEZA Y EL TRABAJO EN SOCIEDADES EXTRACTIVAS. CAPITALISMO Y PATRIARCADO EN EL NEODESARROLLISMO EN LA ARGENTINA
}

\author{
Mariano Féliz ${ }^{1}$
}

Alicia Isabel Migliaro²

\begin{abstract}
RESUMEN
En este trabajo nos proponemos debatir la articulación del capitalismopatriarcal en el contexto del proyecto neodesarrollista en Argentina. Partimos de la consideración del neodesarrollismo como una fase superior del capitalismo dependiente, el cual se asienta en las desigualdades sociales preexistentes, actualizando los mecanismos de dominación y profundizando los sistemas de estratificación social. En primer término, nos abocaremos a captar la especificidad del extractivismo en el capitalismo dependiente contemporáneo. En segundo lugar, analizamos la forma en que se articulan los debates feministas con los análisis del extractivismo, profundizando en una lectura interseccional del extractivismo y en la articulación capitalista-patriarcal. Finalmente, plantearemos como el neodesarrollismo en Argentina se constituyó como una forma específica de producción/reproducción en el capitalismopatriarcal contemporáneo y a la vez una modalidad particular de procesar los procesos conflictivos de apropiación (superexplotación) del trabajo y la naturaleza. Este contexto de expansión capitalista configura un decidido ataque a la reproducción de la vida al que deberemos responder, desde las grietas de un sistema en crisis, radicalizando el compromiso en la construcción de vidas dignas de ser vividas.
\end{abstract}

Palabras claves: Neoxtractivismo, Capitalismo-patriarcal, superexplotación

\section{RESUMO}

Neste artigo, propomos discutir a articulação do capitalismo patriarcal no contexto do projeto neodesenvolvimentista na Argentina. Partimos da consideração do neodesarrollismo como uma fase superior do capitalismo dependente, que se baseia em desigualdades sociais preexistentes, atualizando os mecanismos de dominação e aprofundando os sistemas de estratificação social.Em primeiro lugar, nos concentraremos em captar a especificidade do extrativismo no capitalismo dependente contemporâneo. Em segundo lugar, analisamos a maneira como os debates feministas se articulam com a análise do extrativismo, aprofundando-se em uma leitura intersetorial do extrativismo e na articulação capitalista-patriarcal. Finalmente, vamos levantar

${ }^{1}$ CIG-IdIHCS/CONICET-UNLP.

${ }^{2}$ CIG-IdIHCS/CONICET-UNLP, UDELAR. 
como neo-desenvolvimentismona Argentina foi estabelecida como uma forma específica de capitalismo de produção/reprodução patriarcal contemporânea enquanto uma determinada forma de realização de processos de propriedade de processos conflitantes (super-exploração) o trabalho ea natureza. Esse contexto de expansão capitalista configura um ataque determinado à reprodução da vida a que devemos responder, a partir das fissuras de um sistema em crise, radicalizando o compromisso na construção de vidas dignas de serem vividas.

Palabras chaves: Neoxtractivismo, capitalismo-patriarcal, superexploração

\section{INTRODUCCIÓN}

El capitalismo-patriarcal es un sistema de producción y reproducción social basado en el saqueo de los bienes comunes y la explotación del trabajo. En las sociedades periféricas, dependientes (MARINI, 2015b), estos procesos se multiplican y exacerban, en especial por la conformación de formaciones sociales extractivistas (ZIBECHI, 2017). Lejos de ser un daño colateral, las desigualdades sociales que estos procesos causan se articulan entre sí potenciando los modos de dominación. En ese proceso, capital y Estado -como su forma política (HOLLOWAY, 1992) - operan para reproducir relaciones societales basadas en la destrucción e integración de la vida misma en modalidades explotativas. Hablamos de una contradicción irresoluble que enfrenta la lógica de acumulación mercantil con la sostenibilidad de la vida (CARRASCO BENGOA, 2012, 2014). Los términos del conflicto son claros: Capital vs. Vida (PÉREZ OROZCO, 2014).

Comprender la naturaleza de la desigualdad social en el capitalismo dependiente requiere analizar cómo se articulan las modalidades de explotación de la naturaleza y del trabajo humano en sus diversas formas. En las décadas recientes, en el marco de estrategias neodesarrollistas, en la región suramericana y en particular en Argentina (FÉLIZ, 2015c), esas dinámicas se han producido en formas novedosas profundizando las modalidades de producción societal extractivista, reproduciendo de forma ampliada la superexplotación de la naturaleza y del trabajo.

\section{SAQUEO $Y$ SUPEREXPLOTACIÓN DE LA NATURALEZA: ¿NEOEXTRACTIVISMO COMO FORMA SUPERIOR DEL CAPITALISMO?}

Dice la historia que el capitalismo siempre fue extractivista. El saqueo de las riquezas de la naturaleza estuvo en su nacimiento en las formas de 
colonialismo e imperialismo clásicos (LUXEMBURGO, 2018). Ese saqueo no fue solo de la naturaleza, claro está, la contraparte necesaria fue la apropiación de los cuerpos de varones y mujeres, bajo la forma general de la esclavitud moderna (FEDERICI, 2013; LINEBAUGH \& REDIKER, 2002). En la medida en que el capitalismo se expandió de manera universal, se consolidó también la articulación dependiente de los territorios conformados en torno a los Estadonación.

Dice Marx, sobre acumulación originaria en El Capital, que el capitalismo "viene al mundo chorreando lodo y sangre" (MARX, 1995, p.950). Imagen contundente que resquebraja la edulcorada leyenda de la transición afable de un modelo feudal atrasado a un modelo capitalista moderno. La imposición y el desarrollo del capitalismo suponen una irrupción violenta y un ejercicio coercitivo para apropiarse de los bienes comunes y del trabajo humano en pos de la acumulación de capital. Sumado a esto, las teorías decoloniales, ahondan en la modalidad específica de inserción capitalista en los países periféricos en alianza con mecanismos de estratificación como modos de dominación: género, raza-etnia, etc. La tesis que desarrolla Silvia Federici en Calibán y la Bruja desnuda los mecanismos finos entre expansión del capitalismo y la necesidad de apropiación, control y violencia de las mujeres (FEDERICI, 2010).

Estos procesos cruentos continúan vigentes, reactualizándose en cada oleada de expansión capitalista. Las últimas décadas en Argentina han sido de soja, megaminería, forestación, agrotóxicos, pesca a gran escala. También han sido épocas de despojo, desplazamiento de poblaciones originarias y campesinas, migraciones, violencia hacia las mujeres, precarización de la vida (FÉLIZ, 2015a; MELÓN, 2014; SCANDIZZO, 2016; SVAMPA \& VIALE, 2014).

La dependencia se constituyó como carácter esencial del capitalismo en las periferias en la misma medida en que los países centrales se transformaban en imperialista (LUXEMBURG, 2018; MARINI, 2015a). En estos últimos se consolidaron formas de capitalismo 'industrial' donde las formas de producción de plusvalía relativa y la creciente subordinación real del trabajo al capital. En los primeros predominan, por el contrario, formas de plusvalía absoluta, en particular de superexplotación de la fuerza de trabajo y se conformaron patrones de acumulación de capital extrovertidos y ligados a modalidades de 
producción en las cuales el extractivismo original, histórico, se ve exacerbado e internalizado.

El extractivismo se conforma como una modalidad de saqueo de las riquezas naturales apoyado en formas varias de superexplotación de la fuerza de trabajo. La necesidad de extraer sin límites los medios materiales para la producción y reproducción del capital en los centros imperialistas se acelera y opera buscando superar dialécticamente (es decir, sin poder cancelarla) la tendencia a la desvalorización del capital. En ese proceso, la dialéctica valor de uso - valor es exacerbada hasta los límites de la destrucción social del territorio.

Territorios enteros dentro de los países dependientes se constituyen en vastas extensiones masivamente explotadas, en verdaderas "zonas de sacrificio". Concepto planteado por Steve Lerner (MARTíNEZ ALIER, 2015), para nominar la desarticulación y el daño estructural que el ordenamiento territorial capitalista produce sobre determinadas zonas y poblaciones.

En nombre de la ideología del progreso, las comunidades allí asentadas aparecen invisibilizadas, las economías regionales devaluadas o sus crisis exacerbadas, a fin de facilitar el ingreso de otros proyectos de desarrollo que terminan convirtiéndose en agentes de ocupación territorial (SVAMPA \& VIALE, 2014, p.31).

El extractivismo contemporáneo (neoextractivismo) ha conducido a consolidar y profundizar la fractura del metabolismo universal de la naturaleza, en especial en territorios dependientes. La vida humana y el resto de las formas de la vida han históricamente compartido formas de reproducción socionatural sustentables. Esa relación metabólica entre la humanidad y la naturaleza se encuentra inevitablemente mediada por el trabajo (BELLAMY FOSTER, 2014).

Marxismo mediante, sabido es que los seres humanos transforman la naturaleza a través de su producción, pero no lo hacen como les plazca sino bajo las condiciones heredadas del pasado (de la historia natural y social), y siguen dependiendo de la dinámica básica de la vida y la existencia material. Los seres humanos no existen por sí mismos por fuera, de manera independiente de la naturaleza. En un sentido profundo somos naturaleza. Es 
más, la concepción antropocéntrica propia del pensamiento moderno occidental no hace sino invisibilizar los lazos de interdependencia que los seres humanos y las sociedades tenemos con la naturaleza.

Hoy, en una nueva era geológica, la dinámica de la reproducción de la humanidad se encuentra dominada por el momentum de la valorización del capital (es decir, por el fetichismo de la mercancía). En el Capitaloceno (MOORE, 2017), la reproducción de la vida no humana y, crecientemente, de la vida humana es puesta en peligro. En esta nueva era geológica dominada por la relación social de capital, la naturaleza misma es integrada realmente al capital, subordinada o subsumida en él (SABBATELLA, 2008), constituyéndose en una fuerza productiva a su servicio. Es decir, la naturaleza no es ya 'exterior' al capital (GAGO \& MEZZADRA, 2015, p.47) sino que se constituye como recurso explotable internalizado en el ciclo del capital, de forma tal que tendencial e idealmente- ya no existe naturaleza no capitalizada. Para el capital solo es 'recurso natural' aquello que puede dominar; todo lo que se encuentra por fuera de esa forma, es pasible de ser destruido. De esa forma, la subordinación real de la vida al capital se expande más allá del trabajo hacia la vida misma y el conjunto de la naturaleza no humana.

En tanto se desarrolla este proceso, se activan los límites absolutos del capital que se asocian la destrucción de las condiciones de reproducción metabólica social (MÉSZÁROS, 1995). La tierra como biósfera está llegando a sus límites reproductivos, que son expresión de los límites de la "segunda contradicción fundamental" de la sociedad capitalista (O'CONNOR, 2001). Si la relación capital-trabajo expresa la primera contradicción fundamental, la contradicción entre el capital y la naturaleza (que incluye a los seres humanos y al resto de la vida en la tierra) se torna cada vez más extrema.

Si el extractivismo ha sido siempre parte de la producción y reproducción del capital como relación social dominante, esta modalidad opera en buena parte de los territorios dependientes (en particular en Nuestramérica) como eje articulador de formaciones societales que se han constituido históricamente en tanto tales, es decir, en sociedades extractivistas, es decir sociedades que se basan en la lógica de intensificación de la explotación de la naturaleza y de las relaciones sociales (ZIBECHI, 2017). El saqueo de las riquezas naturales, la 
instrumentalización de la vida incluida Gaia (es decir, la naturaleza misma), asumen modalidades extremas en esos territorios. Producto de las formas del imperialismo en su dimensión ecológica (VEGA CANTOR, 2006), las sociedades dependientes tienden a conformarse bajo modalidades que exacerban la fractura metabólica que resultan de la propensión extractiva del capital.

La potencias imperialistas en su necesidad de multiplicar la apropiación de valores de uso adecuados a las particulares modalidades de producción de valor en el centro, multiplican la presión sobre la naturaleza en los territorios dependientes. En Argentina, por ejemplo, el proceso de sojización y el extractivismo minero se articulan casi perfectamente con las demandas imperialistas: prácticamente la totalidad de la producción de soja y oro (uno de los principales metales extraídos) se destina a satisfacer la demanda de las grandes potencias (FÉLIZ, 2014).

En síntesis, podríamos afirmar que el extractivismo en los territorios dependientes opera en modalidades de superexplotación o saqueo de los bienes comunes. Nada a lo que no nos hayamos acostumbrado desde la colonia hasta nuestros días. Sin embargo, como señalamos, si bien los mecanismos de saqueo y explotación son intrínsecos al capitalismo, los desarrollos tecnológicos, la especulación financiera y las nuevas necesidades del ciclo de valorización del capital en el centro (y su crisis actual), han intensificado la presión del capital por sobre los bienes comunes hasta límites inimaginados. Por lo tanto si bien estrictamente el neoextractivismo no imprime ninguna dinámica novedosa en el patrón de acumulación del capital, si hay algo "neo" que se capta como percepción de síntesis en un ciclo que sé ha acelerado de usufructo de los bienes comunes.

El neo-extractivismo da cuenta ya no solo de características vinculadas a espacios periféricos de la economía (típicos de las formas de economía de enclave) sino que expresa "rasgos preponderantes de las operaciones del capital en sectores estratégicos de su desarrollo actual -de lo territorial a lo digital, pasando por lo financiero-" (GAGO \& MEZZADRA, 2015, p.43). Además, la conciencia de mundo global que se comienza a crear a partir de fines de la década de los '70 (TOMMASINO, FOLADORI, \& TAKS, 2005) ofrece 
nuevas escalas interpretativas sobre el rol de las crisis económicas, la degradación ambiental y la violencia estructural hacia las mujeres. El desarrollo el pensamiento feminista y ecologista (con un desarrollo en paralelo aunque con marcadas sintonías) esgrimirá duras críticas a los modos de opresión de las mujeres y la naturaleza, advirtiendo los riesgos de la fe ciega en el crecimiento ilimitado.

\section{MUJERES Y NATURALEZA EN MANOS DEL CAPITAL: LA INEVITABLE PROFUNDIZACIÓN DE LAS DESIGUALDADES}

Un sistema profundamente injusto origina una crisis profundamente injusta; sobre la desigualdad social estructural se delinean las desigualdades ambientales. Las desigualdades ambientales se manifiestan como asimetrías de poder en dos claves: (i) acceso y usufructo de los bienes comunes esenciales para la vida y (ii) distribución de las externalidades negativas en el ambiente (SABBATELLA, 2008). La ecología política es el campo de conocimiento que se ha ocupado de comprender las relaciones ecológicas como relaciones sociales atravesadas por nociones de poder. Nociones como la "injusticia ambiental" (ACSELARD, CAMPELLO AMARAL MELLO \& das NEVES BEZERRA, 2009) o los "conflictos ecológicos distributivos" (MARTÍNEZ ALLIER, 2004) proponen una mirada de la problemática ecológica atravesada por relaciones de poder. La díada "justicia-injusticia ambiental" (ACSELARD et al., 2009) conceptualiza la injusticia como la expresión de las desigualdades sociales estructurales en la esfera ambiental, la cual se constituye a su vez como una nueva desigualdad.

Los conflictos ecológicos distributivos (MARTíNEZ ALLIER, 2004) se asientan sobre la distribución desigual de los costos y beneficios de la explotación ambiental, a la vez que por sobre las diferentes valoraciones que los actores realizan sobre un mismo bien natural. A modo de ejemplo, un río puede ser un curso de agua con potencial para la generación de energía hidroeléctrica o puede ser el agua que guarda la memoria espiritual de una comunidad. El río es el mismo, lo que cambia radicalmente, es la concepción sobre él y por ende los modos posibles vinculación y usufructo.

Sumado a esto, los aportes del feminismo a la ecología política y la 
AMBIENTE \& EDUCAÇÃo

ISSN- 1413-8638

E-ISSN - 2238-5533

v. 23, n. 3, p. 201-229, 2018

geografía crítica, advierten que si pensamos los territorios estructurados por relaciones de poder, necesariamente debemos considerar las desigualdades de género en juego. El territorio como espacio estriado en donde se producen y reproducen desigualdades de clase, género y étnico-raciales, configurándose también, como un espacio de disputa (COLECTIVO GEOGRAFÍA CRÍTICA DEL ECUADOR, 2018). ¿Podemos pensar en un "ecologismo de las pobres"? ¿Qué rasgos tendrán estas mujeres? ¿En qué lenguas expresan sus luchas?

Ahondando en esta clave encontramos con los aportes de los Ecofeminismos como una renovada perspectiva a la dominación de la sociedad capitalista patriarcal sobre las mujeres y la naturaleza. Surge en el entorno de los años '70 (aunque sus raíces filosóficas puedan rastrearse hasta los debates de la llustración), de la mano de los planteos de Francoise d'Eaubonne. Es un enfoque reciente, abierto, plural y diverso, que ha cobrado importancia en el campo de la lucha política, mayoritariamente de los países periféricos (América Latina, África y Asia), retomando la preocupación por la vida humana en relaciones sociales y ecológicas sustentables (PULEO, 2011).

Los años setenta comenzaron a movilizar a las 'dominadas'. Vieron nacer movimientos de mujeres y movimientos ecológicos de diferentes tendencias, anunciando el fin de la hegemonía del imperio patriarcal. $Y$ es de esa conjunción creativa de donde nace y crece el ecofeminismo. (GEBARA, 2000: 11)

El ecofeminismo, en sus distintas corrientes, cuestiona la alianza entre patriarcado, capitalismo y dominación de la naturaleza, y el ideal desarrollista hegemónico. "Esta perspectiva patriarcal-capitalista interpreta la diferencia como jerarquía y la uniformidad como requisito previo para la igualdad" (MIES \& SHIVA, 1997, p.8). Algunas voces críticas dentro del ecofeminismo enfatizan la necesidad de considerar las relaciones materiales entre mujeres y naturaleza, evitando caer en esencialismo que invisibilizan las diferencias entre las mujeres.

"Me gustaría sugerir aquí que la relación de las mujeres y los hombres con la naturaleza necesita ser entendida como fundamentada en su realidad material, en sus formas específicas de interacción con el medioambiente. De aquí que en la medida en que hay una división del trabajo y una distribución de la propiedad y el poder basadas en el género y la clase (casta/raza), el género y la clase (casta/raza) estructuran las interacciones de las personas con la naturaleza y, así, estructuran los efectos del cambio 
medioambiental en las personas y sus respuestas al mismo. (...) Por lo tanto, en esta conceptualización el vínculo entre las mujeres y el medioambiente puede ser visto como estructurado por una organización de producción, reproducción y distribución dada en base al género y la clase (casta/raza)" (AGARWAL, 1992, p.184).

En la ya clásica tipología que propone Puleo (2011) se distinguen cuatro corrientes principales del ecofeminismo: (i) clásico o espiritualista, (ii) liberal o ambientalista de género, (iii) multiculturalista o del sur, (iv) constructivista 0 feminismo ecológico. La sintonía entre distintas corrientes se encuentra en la denuncia del orden androcéntrco-capitalista, en la comprensión multicausal de la dominación y en la necesidad de proponer alternativas para la crisis socialambiental global (GEBARA, 2000; PULEO, 2005).

Ahora bien, ¿cómo cuajan los debates del Ecofeminismo en la coyuntura de Nuestramérica? El contexto neoextractivista y neodesarrollista, la presión sobre los bienes comunes y el despojo ha encontrado resistencias. Resistencias en manos de mujeres que, literalmente, han puesto el cuerpo para frenar el saqueo. Liderazgos femeninos fuertes y contundentes nos llevan a mirar el proceso que aúna la lucha contra el extractivismo y el feminismo en la construcción de vidas dignas de ser vividas. A propósito de esto, Peredo Beltrán (2017) esboza la posibilidad de considerar una quinta corriente del Ecofeminismo que, plasmada en el grito de lucha "Mi cuerpo mi territorio", emerge en el ciclo de luchas contra el neodesarrollismo y neoxtractivismo (PEREDO BELTRÁN, 2017). Esta corriente, de expresión reciente, encontrará en mujeres populares y diversas una fuerza contrahegemónica y una posibilidad certera de freno al proyecto devastador del capital.

\section{El patriarcado como mediación entre el extractivismo y la dependencia}

El saqueo extractivista se asienta sobre las desigualdades sociales estructurales y por ende abre niveles crecientes de estratificación en injusticia social. La superexplotación del trabajo y la naturaleza, la violencia y el control sobre los cuerpos y territorios, son rasgo que se imprimen como huellas en los territorios del extractivismo. La imposición de la racionalidad capitalista legitima la destrucción y contaminación total de vastas zonas de nuestro planeta. Necesario es considerar las "poblaciones de sacrificio" que se subsumen en 
estas racionalidades (BOLADOS GARCÍA \& SÁNCHEZ CUEVAS, 2017). Poblaciones pobres, racializadas, sexualizadas, como bienes fungibles del modelo extractivista.

La alianza capitalismo-patriarcado-extractivismo en contextos dependientes se configura como tríada constitutiva $y$, de manera renovada, sesgo distintivo de la etapa actual. Simple constatación empírica, alcanza con observar que poblaciones pagan los costos del extractivismo y heterogeneizar, las diferencias de clase, género, raza, generaciones. El desafío es poder abordar estas multiplicidades de desigualdades evidenciando los mecanismos finos de esta alianza.

Existe una colaboración entre patriarcado y capitalismo, una colaboración que permite aunar dos sistemas de opresión y potenciar sus efectos (ARRUZZA, 2015; DALLA COSTA, 1972; FEDERICI, 2010; HARTMANN, 1980). Podemos entender mejor el funcionamiento de nuestras sociedades si agudizamos la mirada sobre la relación entre capitalismo y patriarcado. La acumulación del capital se acomoda a la estructura social patriarcal y contribuye a perpetuarla, y a su vez la ideología sexista ha asumido una formación que tienden a apuntalar el desarrollo del capitalismo.

Sin embargo, ¿cómo opera esta alianza? La dificultad para leer las relaciones entre capitalismo y patriarcado se basan en que, en apariencia, el capitalismo es un sistema de dominación social que opera en la esfera pública y el patriarcado en la privada.

Podemos definir el patriarcado como un conjunto de relaciones sociales entre los hombres que tienen una base material y que, si bien son jerárquicas, establecen o crean una interdependencia y solidaridad entre los hombres que les permiten dominar a las mujeres. Si bien el patriarcado es jerárquico y los hombres de las distintas clases, razas o grupos étnicos ocupan distintos puestos en el patriarcado, también les une su común relación de dominación sobre sus mujeres; dependen unos de otros para mantener esta dominación. Las jerarquías "funcionan" al menos en parte porque crean un interés personal en mantener el status quo. Los que están situados en los niveles superiores pueden "comprar" a los que están en los inferiores ofreciéndoles poder sobre los que están aún más abajo. En la jerarquía del patriarcado, todos los hombres, sea cual fuere su rango en el patriarcado, son comprados mediante la posibilidad de controlar al menos a algunas mujeres (...) Los hombres dependen unos de otros (a pesar de su ordenamiento jerárquico) para mantener su control sobre las mujeres. (HARTMANN, 1980: 12) 
En la misma línea avanza Silvia Federici cuando plantea que el capitalismo avanza a costa de convertir a las mujeres (su cuerpo, su fuerza de trabajo, su sabiduría) en "comunes", a explotarlas en pos del desarrollo del sistema y a establecer sucesivos mecanismos de mediación entre las mujeres y sus producciones (AGUILAR, SOSA, \& REYES, 2018). Es decir, la posibilidad de expansión por sobre nuevos territorios requiere renovar el pacto de alianza capitalismo-patriarcado apelando a conocidas y efectivas formas de estratificación y jerarquización social.

Ahora bien, no basta con enunciar las diferentes dimensiones de las desigualdades ni advertir la colaboración mutua para perpetuar la opresión. Precisamos sustentos epistemológicos que nos permitan entender cómo las desigualdades encarnan en sujetos concretos, comprenderlas en las experiencias vitales de los sujetos. Vale decir, las categorías que se nos presentan como naturales y transparentes, lejos están de serlo. Por el contrario, son construcciones socio-históricas, modelos para acercarse a comprender la dinámica, por ende son abstracciones que difícilmente se manifiesten en forma pura.

Para abordar cómo las opresiones hacen carne en los sujetos nos valemos del concepto feminista interseccionalidad. Este concepto fue enunciado, inicialmente como un concepto de valor empírico por la abogada Kimberlé Crenshawen el marco de una contienda legal entre trabajadoras negras y la empresa General Motors (VIVEROS VIGOYA, 2016). Hacia la década de los ochenta en América Latina comienza a propiciar el debate del llamado feminismo disidente (mujeres negras, de pueblos originarios, lesbianas, trans) quienes empezaron a criticar al feminismo su desconsideración hacia feminidades no hegemónicas. La relevancia política y epistemológica se da a partir de la vinculación con la línea del pensamiento decolonial, desde el cual el sujeto social tiene que ser abordado necesariamente desde su heterogeniedad. Pensamos la interseccionalidad como una categoría de análisis imbricada en trayectorias vitales, la cual está presente incluso antes que las sujetas la signifiquen como tal. Entendemos que, en tanto las matrices hegemónicas para pensar las desigualdades tienen tradiciones diversas, la advertencia sobre las relaciones que establecemos 
entre las mismas siguen siendo válidas principalmente a la hora de pensar este modelo en aplicación empírica.

El capital domina, organiza y se desarrolla a través del salario (FEDERICI, 2018). Un mecanismo fundamental del fenómeno de acumulación originaria, reactualizado en cada proceso de expansión del capital, es el de instaurar relaciones sociales mediadas por el salario. Las feministas marxistas de los setenta abrieron nuevas lecturas sobre el mecanismo de asalariamiento como estrategia de control social en articulación con la división sexual del trabajo.

En sociedades precapitalistas la unidad productiva y reproductiva convive en una misma esfera, siendo la casa el eje central del sostén de la vida. Lejos de lecturas románticas de lo que se da cuenta aquí es de la unidad de hombres, mujeres, niños/as, jóvenes y viejos/as en una circularidad que no distingue entre producción y reproducción, una "unidad de los no libres" (DALLA COSTA, 1972: 3).

El capitalismo descompone esta unidad en al menos tres esferas: la casa, la fábrica y la escuela. En el esquema de la familia heteronormativa tradicional: los hombres a la fábrica, los niños/as a la escuela y las mujeres a la casa. De esta forma, el salario que recibe el varón permite controlar una porción mucho mayor que la que figura en el contrato de la fábrica. Lo que el salario oculta permite invisibilizar otras esferas productivas y origina un comportamiento guetizado, de completa ajenidad entre la escuela, la casa y la fábrica y por ende entre niñxs, mujeres y hombres. Independientemente que las mujeres también trabajen fuera de sus casas o que los niñxs y jóvenes también lo hagan, la división sexual del trabajo se derrama como organizador social, de modo tal que las mujeres no pueden renunciar a su trabajo de "amas de casa" ni los niños/as a su trabajo de "estudiante", denegando todo lo que se produce por fuera. Este mecanismo es un potente succionador de plusvalía absoluta que demuestra la alianza entre las esferas productivas y reproductivas y entre lo material y lo cultural (DALLA COSTA, 1972). Este velo se refleja en las lecturas del marxismo canónico que esgrimió la lucha de clase, y particularmente la lucha de los trabajadores/as asalariados/as, como única trinchera de lucha anticapitalista. Las luchas de las mujeres, las luchas 
comunitarias, las revueltas y movimientos juveniles son mirados con desdén y hasta con desconfianza, como una fuga de energía o como un error estratégico.

\section{Patriarcado, saqueo y superexplotación}

El neoextractivismo en América Latina no surge por generación espontánea sino que se asienta en delicado sistema de dominación prexistente (SILVA SANTISTEBAN, 2017) y se alía a formas renovadas de superexplotación del trabajo. En la fase actual supone un uso intensivo de los bienes comunes (extraer más en el menor tiempo posible), así como una hegemonización de la direccionalidad del desarrollo (la única alternativa es la generación de commodities) de manera de reproducir a escala ampliada las relaciones que estructuran la posición dependiente del capitalismo en Nuestramérica. La creciente expansión neoextractivista implica una reconfiguración de las relaciones sociales territoriales en la cual se acentúa la división sexual del trabajo, los procesos de descalificación y precarización laboral, así como la apropiación del trabajo reproductivo que realizan las mujeres.

García Torres (2017) plantea que el extractivismo supone una patriarcalización del territorio por tres motivos principales. En primer lugar promueve una alianza entre varones (entre las empresas y los trabajadores de las comunidades locales) proponiendo una lógica masculinizada en la toma de decisiones. En segundo lugar acentúa la división social del trabajo al emplear mayoritariamente varones para tareas de fuerza y desgaste físico (quienes en general pasan a tener un salario fijo) relegando a las mujeres el trabajo de servicios (generalmente en modalidad de cuentapropistas y de baja remuneración). Por último, el extractivismo supone un disciplinamiento y control del cuerpo de las mujeres en los territorios mediante el ejercicio de la violencia y la explotación sexual.

Para pensar la permeación de las lógicas patriarcales foráneas en las comunidades resulta útil el concepto de patriarcado dependiente desarrollado por Danilo Clímaco de Assis (SILVA SANTISTEBAN, 2017). La matriz colonial, 
articulada entre la dimensión de clase y la étnico racial, sienta las bases para el establecimiento de un pacto desigual entre las élites masculinas colonizadoras y los varones de los pueblos "a colonizar". En este pacto desigual, la ventaja relativa de los varones "a colonizar" es la posibilidad de superexplotación del trabajo de las mujeres (trabajo reproductivo y de cuidado invisibilizado) y de usufructo de su cuerpo (violencia y abuso sexual). El patriarcado y la dependencia se resignifica en tiempos de expansión del capital, perpetuando los modos de opresión sobre las mujeres y los cuerpos racializados. El capitalismo dependiente en Nuestramérica integra de manera orgánica al patriarcado dependiente, que opera como instrumento para la ampliación de las formas de explotación absolutas de la fuerza de trabajo. Si como decía Marini (2015) el capital en espacios dependientes usa la superexplotación para compensar las presiones del intercambio desigual, los varones en contextos dependientes 'compensan' formas de superexplotación de su fuerza de trabajo bajo modalidades de superexplotación y dominación exacerbadas del trabajo y cuerpo de las mujeres. El patriarcado y el capitalismo dependiente crean una matríz de apropiación del trabajo de las mujeres a los fines de la apropiación capitalista en el centro.

Los mecanismos de violencia y dominación de las mujeres planteados por Silvia Federici al describir el proceso de acumulación originaria (FEDERICI, 2010) tiene plena vigencia en la actualidad (CIELO \& VEGA, 2015). El neoextractivismo impone una racionalidad exclusiva y excluyente en el territorio, apropiándose de grandes extensiones de tierra y bienes comunes y fragmentando los modos tradicionales de vinculación comunal entre comunidad y naturaleza. De esa manera, recoloca a las economías dependientes en los nuevos circuitos internacionalizados de valorización del capital. En el trabajo ofertado por el neoextractivismo, la mediación salarial captura el trabajo en la forma empleo y rigidiza la división sexual del trabajo. De aquí en más el abaratamiento de la mano de obra será, una variable de ajuste para reducir los costos de producción, en un monto salarial que nunca alcanza a costear la totalidad de la reproducción de la fuerza de trabajo, sustentándose de facto, en el trabajo no pagado a las mujeres (CARRASCO BENGOA, 2014; PÉREZ OROZCO, 2014). 
(...) la desposesión territorial para la acumulación originaria del capital en sus continuas reediciones en el Sur global no se puede entender hoy solamente como parte de reconfiguraciones sociales, políticas y económicas. Federici demuestra de manera fehaciente las formas en que la instauración del capitalismo depende de la escisión entre trabajo productivo y reproductivo, así como el despojo del poder de la mujer (...). (CIELO \& VEGA, 2015: 140)

Estos procesos de opresión se instalan y perpetúan a partir de las prácticas de mediación patriarcal que suponen la intermediación de lógicas masculinas en la relación de las mujeres entre sí y con sus productos (AGUILAR ET AL., 2018). Es este un mecanismo sutil de opresión que no implica meramente inhibir la producción o la colaboración entre mujeres, sino que supone un mecanismo de captura de la agencia de las mujeres. Vale decir que todo lo que producen las mujeres, singular o colectivamente, se reconoce (y por ende se significa) a partir de la inscripción en un orden simbólico masculino. Una suerte de sumidero capitalista-patriarcal que succiona la energía creativa femenina y la coloca al servicio de la reproducción del sistema.

\section{NEODESARROLLISMO EN ARGENTINA, COMO FORMA Y ESTRATEGIA DEL SAQUEO DE LAS RIQUEZAS NATURALES Y EL TRABAJO}

Las últimas dos décadas han visto a buena parte de Latinoamérica atravesar procesos de superación dialéctica del neoliberalismo (FÉLIZ, 2015c). Esos procesos han llevado al subcontinente hacia una nueva etapa en su desarrollo capitalista. El neodesarrollismo ha irrumpido como estrategia del gran capital transnacional en la región para volver a desplegar su valorización ampliada sobre nuevas bases (FÉLIZ, 2015b). En Argentina, ese proceso histórico avanzó de manera contradictoria desde la crisis orgánica de 2001/2002 (FÉLIZ, 2019).

En esta nueva era, de dominio del capital transnacionalizado, la fase extractivista se exacerba a partir de las nuevas modalidades de apropiación y superexplotación de la naturaleza y el trabajo, en marcos articulados con el patriarcado. La subordinación real de la primera al capital se hace más presente. La superexplotación laboral se consolida como complemento perfecto de aquella. Simultáneamente, se acentúa la transnacionalización del patriarcado (FALQUET, 2014). Se constituyen rutas internacionales de cuidados, donde migrantes mujeres de las periferias pasan a ocupar el rol de 
'reproductoras' en familias de clases medias y medias altar en los países centrales $o$ en los 'centros de la periferia' (especialmente, en grandes ciudades). El trabajo productivo y reproductivo (y cuidados) se integra más plenamente al saqueo de las riquezas naturales y los comunes, estableciéndose una imbricación cada vez más orgánica de unos y otros.

El neodesarrollismo constituye una nueva forma del capitalismo en las economías dependientes. En particular, opera en Argentina (de manera similar al resto de Nuestramérica) como estrategia para ampliar las bases del saqueo de la naturaleza y la vida. La minería, la explotación de hidrocarburos, la producción de energía, la producción de alimentos y aun la producción del hábitat urbano, se desarrollan ahora bajo modalidades a escalas nunca vistas (MACHADO ARÁOZ, 2013). La masa de capital constante fijo (maquinaria) y circulante (materias primas, insumos) en operación es tan elevada que la destrucción de los sistemas ecosociales es brutal. De tal forma, ocurre que el capital se enfrenta en la actualidad a una nueva etapa en donde los límites absolutos del capital se manifiestan bajo la forma de una aparente crisis de subproducción de 'recursos naturales' (O'CONNOR, 2001; SABBATELLA, 2008). El neoextractivismo supone multiplicación exponencial de los costos de producción y de los costos ambientales de las explotaciones.

Como señalamos, la ampliación en la escala del saqueo es expresión de las dificultades crecientes del capital para ampliar su valorización. El neodesarrollo como estrategia abre un nueva etapa en el proceso de dominación y explotación múltiple (VALDÉZ GUTIERREZ, 2002) a los fines de superar dialécticamente tales límites. La expropiación multiplicada de la naturaleza tiene como contracara la expropiación aún más exhaustiva del trabajo productivo y reproductivo, en nuevas modalidades de superexplotación.

La dinámica de valorización del capital compensa las enormes masas de trabajo muerto invertidas en los procesos extractivistas con el aumento de la superexplotación del trabajo vivo en los procesos de circulación de mercancías y sus manufactura. En efecto, la mecanización de los procesos extractivistas contemporáneos, pone enorme presión sobre el resto del capital que opera en el territorio para apropiar valor. Las nuevas tecnologías de extracción operan en escalas harto mayores (mega-) multiplicando el procesamiento de riquezas 
naturales por unidad de tiempo pero llevando al límite -simultáneamente- el plusvalor directamente disponible.

Si históricamente el flujo desigual de valor de la periferia al centro era la base de la dependencia (MARINI, 2015a), la exacerbación extractivista amplía las tensiones en esa dirección. La posición subordinada de la economía dependiente en la división internacional del trabajo, ha creado un proceso de intercambio desigual de valores de uso y valor, de trabajo concreto y abstracto, que ha impedido -y aún lo hace- la superación de las condiciones de subdesarrollo capitalista.

Dado que es la explotación del trabajo vivo la base de la producción de plusvalía, en la actualidad el desarrollo de actividades con crecientes volúmenes de trabajo muerto (capital constante, maquinaria e insumos no humanos) supone la multiplicación de formas de superexplotación del trabajo productivo y reproductivo a modo de compensación. El incremento superlativo de la composición orgánica del capital (coc) en las actividades neoextractivistas, reduce -relativamente- la fracción del capital (capital variable) capaz de producir excedente bajo la forma de plusvalor. De allí que las ganancias apropiadas en las ramas neoextractivistas, con elevados niveles de coc, requieran -cada vez en mayor medida- de la apropiación de plusvalía creada en la explotación del trabajo en otras ramas.

El neoextractivismo opera, primero, bajo la lógica imperial, destinando a los territorios periféricos la producción de los medios materiales (valores de uso) para la producción capitalista en el centro. Ese proceso pretende aparecer como modernización, la otra cara de la avanzada imperial (VEGA CANTOR, 2006). En Argentina, desde la etapa neodesarrollista, casi la totalidad de la soja producida y el oro extraído, por ejemplo, tienen -como señalamos- destino directo de exportación hacia las potencias imperialistas (EE.UU., Unión Europea) o subimperialista (China).

La modernización del saqueo avanza sobre los territorios históricamente ocupados por los pueblos originarios. De allí, que no pueda avanzar sin apelar a una cuota creciente de racismo y represión tanto estatal como paraestatal. La modernización siempre se pretende progresiva, y promete convertir el 'atraso ancestral' en nuevos El Dorado (SVAMPA \& VIALE, 2014). En Argentina, la 
batallas políticas, sociales, culturales, recientes en torno a los territorios Mapuche debajo de los cuales se han descubierto enormes reservas de hidrocarburos (yacimientos de la formación geológica Vaca Muerta) son ejemplo de esta dinámica que pretende expulsar a las comunidades de sus territorios ancestrales (PÉREZ ROIG, SCANDIZZO, \& di RISIO, 2016).

A la vez, el avance del neoextractivismo requiere, en segundo lugar, ampliar la explotación general del trabajo colectivo. Valorizar las enormes masas de capital constante, trabajo muerto incapaz de crear plusvalor, supone ampliar considerablemente la base de superexplotación del trabajo remunerado en los territorios aledaños, en las actividades conexas, en el transporte o el procesamiento de los bienes comunes mercantilizados. La paradoja es tal, que -por ello- la industrialización complementaria al extractivismo no puede romper con los patrones de superexplotación del trabajo remunerado. Al contrario, el saqueo contemporáneo requiere de esas modalidades de precarización como sustento para la valorización del capital extractivo de elevada composición orgánica. De esta forma, mientras las ramas extractivistas operan con aparentes niveles de alta productividad laboral, conviven con -y sobreviven gracias a- prácticas de superexplotación de la fuerza de trabajo en el conjunto del ciclo del capital en el territorio.

En este sentido, el trabajo de las mujeres en fábricas tipo maquila ejemplifica esta dinámica donde la superexplotación del trabajo productivo es el fundamento mismo de la existencia de esas actividades. A su vez, esta superexplotación del trabajo se apoya en un ejercicio denotado de la violencia física, sexual y psicológica hacia las mujeres trabajadoras. El tipo de trabajo (seriado, poco calificado), los territorios en que se instalan (territorios fronterizos de la periferia mundial) y la violencia hacia las mujeres actúan como factores entrelazados para el abaratamiento del costo de la fuerza de trabajo (SEGATO, 2013). Otra cara de este mecanismo de superexplotación lo encontramos en los casos de contaminación, enfermedad y fallecimiento de trabajadores vinculados a la industria extractiva, por ejemplo las poblaciones de los "pueblos fumigados" en las regiones de la Argentina donde se concentra la producción sojera. Esta producción es prototípica de las nuevas modalidades extractivas altamente tecnologizadas, con formas financiarizadas de gestión e 
intensivas en capital constante (agrotóxicos, maquinarias, semillas transgénicas).

Tercero, la producción neoextractivista amplía la superexplotación del trabajo de reproducción y multiplica las formas de la violencia de género. A través de las políticas sociales del universalismo básico, se conforma una red de cobertura elemental que contiene la conflictividad social a la vez que reproduce las modalidades patriarcales de reproducción de la vida (FÉLIZ Y DÍAZ LOZANO, 2018). La combinación de la ampliación del acceso de las mujeres al mercado de trabajo, el deterioro de los servicios provistos por los precarios Estados de Bienestar periféricos y la desarticulación de las formas comunitarias, colectivas, de organización de la reproducción de la vida, coloca a las mujeres en el centro mismo del extractivismo desarrollista contemporáneo. La extracción de plustrabajo femenino se multiplica en la medida en que la internacionalización del capital constituye de manera tendencial una fuerza de trabajo productiva/reproductiva realmente internacionalizada. El trabajo reproductivo funge realmente abstracto, aportando un flujo creciente de tiempo socialmente necesario a la constitución de la plusvalía en las fracciones extractivistas del capital. Un ejemplo de esto es la diagramación del trabajo de cuidados en el capitalismo actual. A pesar de los titánicos avances tecnológicos (productivos y sociales) hay algunas tareas que solo pueden ser realizadas por otro ser humano. Nos referimos particularmente a las tareas de cuidados. Tareas que, división sexual del trabajo mediante, han sido feminizadas y por ende degradadas. En una tendencia creciente vemos como mujeres de países periféricos (o de territorios periféricos dentro de la periferia) migran para trabajar como empleadas cuidando niños/as o ancianos/as, dejando a sus propias familias en sus lugares de origen ${ }^{3}$. El envío de remesas de estas mujeres se convierte en un valioso aporte para el sustento de la familia de origen. Esta situación tiene por un lado la cara de sociedades más o menos desarrolladas que pasan a ser grandes consumidores del trabajo de cuidado como mercancía. La mercantilización de las tareas de cuidados es un ejemplo más de captura del capital sobre la lógica

3 Para el caso argentino esta situación se ve claramente con las migrantes latinoamericanas que se desplazan de sus países de origen en forma más o menos precaria (pero siempre en desventaja) para trabajar como empleadas domésticas o en hogares de ancianos/as. 
de los comunes, con su consiguiente inscripción en el orden capitalista mundial (VEGA SOLís, 2009). Claramente los trabajos de cuidados no salarizados -nos referimos a las modalidades "tradicionales" de cuidados en el seno de la familia o comunidad próxima- estaban organizados sobre un régimen de dominación capitalista patriarcal; la mercantilización de los mismos, lejos de abolir este mecanismo de dominación, amplía el patrón de acumulación. La fuerza de trabajo de los cuidados es apropiada por mujeres de otra clase social y condición étnico-racial (DALLA COSTA, 1972; FEDERICI, 2013). La contracara es el vacío de cuidados que se produce en la familia de origen, el cual, frecuentemente se vale de la sobreexplotación de otra mujer (abuela, tía, hermana) que queda al cuidado de todos los niños/as.

Arlie Russell Hochschild, desarrolla el concepto de "extractivismo afectivo" para nominar esta clave de superexplotación anclado en estrategias geopolíticas de sexualización y racialización de la fuerza de trabajo.

\footnotetext{
"Cuando una niñera tailandesa que trabajo en Redwood City, California, me dice que quiere más a los niños estadounidenses que a los hijos que dejó en Tailandia ¿debo encontrar allí ejemplos de un país rico que 'extrae' de un país pobre el valioso metal del amor? (...) Emoción, género, familia, capitalismo, globalización: estos son los temas" (HOCHSCHILD, 2008: 11)
}

En paralelo, la exacerbación de las formas extractivas promueve prácticas de subjetivación violentas que reproducen -en espejo- la crueldad hacia la naturaleza, las mujeres, las comunidades originarias, y todas aquellas sujetas no hegemónicas. La naturalización de la 'pedagogía de la crueldad' (SEGATO, 2013) se convierte en el patrón de subjetivación constitutivo de las sociedades extractivas contemporáneas. El disciplinamiento mediante la violencia sistemática se evidencia, territorialmente, en las rutas paralelas entre extractivismo y trata de mujeres con fines de explotación sexual, como señala Fabiana Tuñez:

Todos los lugares donde hay un movimiento de la economía que le permite generar más ingresos y más dividendos son objeto de redes de trata. Por eso las organizaciones que trabajamos en este tema sabemos que mayoritariamente la ruta del petróleo, la ruta de la soja, la ruta del turismo sexual y la ruta de eventos deportivos internacional o nacionales están en la mira de las redes de trata (SCANDIZZO, 2010: 122) 
$Y$ este hecho no es nada novedoso, desde principios del S.XX las campañas de colonización sobre territorios "bárbaros" suponían un contingente de varones consumidores de servicios sexuales. Lejos de cualquier mirada romántica sobre el pasado, se advierte un aumento de la violencia y una diferenciación en los modos de reclutamiento y "consumo" actual. Se demandan mujeres más jóvenes, de otras regiones del país o del continente (SCANDIZZO, 2010). En suma mujeres más "anonimizables" con las que el vínculo de proximidad sea el menor posible.

Esta imbricación de mecanismos de opresión, obliga a repensar las respuestas desde los colectivos y organizaciones sociales. Es este el caso de las mujeres de las Salamanqueras del Valle de Famatina, que tras más de doce años de lucha contra la minería, entienden que la fuerza colectivo se debe a la organización de las mujeres y, principalmente, a la capacidad de deconstruir los roles naturalizados.

No solo está en defensa de un cerro, o de los cerros o en contra de la minería; sino que ha entendido que el extractivismo y el capitalismo son lo mismo y que tienen un brazo importante que es el patriarcado y el machismo. $Y$ que si nosotras no empezamos a repensar y a reflexionar sobre nuestras propias prácticas machistas como para luego defendernos de las prácticas machistas del patriarcado de nuestros pueblos y gobernantes no podemos seguir (LUJÁN, 2017).

En síntesis, entendemos que estos modos de sexualizar y racializar a los/as sujetos es una estrategia central en el marco del neodesarrollismo, en tanto permite aprovechar sinérgicamente distintas dimensiones de desigualdad social. Este aprovechamiento no es sólamente cultural o producto de una contradicción secundaria del capital. El aprovechamiento de la dominación es económica, política y social, pues el ordenamiento de los cuerpos y territorios para la captura del capital es un procesos global y totalizante.

\section{CONCLUSIONES PRELIMINARES, MÁS PREGUNTAS QUE RESPUESTAS}


Las sociedades dependientes contemporáneas se encuentran atravesadas por la contradicción integral capitalismo-patriarcal-extractivismo. Comprender esta contradicción es clave para abordar el problema de las luchas emancipatorias, para entender de qué manera esas intersecciones son los núcleos de la potencia de liberación radical. Para la comprensión de este entramado hay que recurrir tanto al análisis marxista (abogamos aquí por un marxismo heterodoxo, en particular la utilización del método históricomaterialista) como al análisis feminista (nos referimos a la identificación del patriarcado como estructura social e histórica).

La forma específica del desarrollo capitalista dependiente articula nuevas modalidades de explotación de la naturaleza, el trabajo y los cuerpos. Por una parte, el neoextractivismo multiplica el saqueo de las riquezas naturales y los comunes, dando un salto cualitativo en tanto en la escala de destrucción de la vida como en la integración de la naturaleza al capital. Por otra parte, la superexplotación del trabajo se encuentra ampliada y diversificada a la superexplotación de la naturaleza. La alianza patriarcado-capitalismo opera aquí como sustrato que permite entender la multiplicación de la valorización del valor mediada por formas extrema(da)s de saqueo y rapiña de la naturaleza y los cuerpos de las mujeres.

La crisis civilizatoria que atravesamos es una crisis estructural del capital a escala global, una crisis de la reproducción social. En el capitalismo dependiente esta crisis de la vida misma, se manifiesta en formas extremas de destrucción, articulando formas de daño irreparables a las comunidades con formas de producción de valor que destruyen las bases naturales-humanas de la reproducción misma. Asimismo, es en esos puntos de mayor explotación donde se expresan los conflictos radicales hoy día. Allí en los bordes, en los márgenes, donde la supervivencia es puesta en riesgo inminente, se perfilan los conflictos que aportan las categorías teóricas críticas: en las luchas feministas, las luchas ecoterritoriales, de pueblos originarios y campesino, en las luchas de los movimientos territoriales urbanos. De allí surgirá las nuevas formas de rechazo radical a la destrucción impuesta por el capital en la hora actual. 


\section{REFERENCIAS BIBLIOGRÁFICAS}

AGARWAL, B. "The Gender and Environment Debate: Lessons from India". Feminist Studies, 18(1), 119-158, 1992. https://doi.org/10.2307/3178217

AGUILAR, R. G., SOSA, M. N., \& REYES, I. "El entre mujeres como negación de las formas de interdependencia impuestas por el patriarcado capitalista y colonial. Reflexiones en torno a la violencia y la mediación patriarcal". Heterotopías, $\quad 0(1), \quad 2018$. Recuperado a partir de https://revistas.unc.edu.ar/index.php/heterotopias/article/view/20007

ARRUZZA, C. Las sin parte. Matrimonios y divorcios entre Feminismo y Marxismo. 1ra ed. Barcelona: Editorial Sylone, 2015.

ASCELARD, H., CAMPELLO AMARAL MELLO, C., \& DAS NEVES BEZERRA, G. O que é justiça ambiental. Río de Janeiro - Brasil: Editora Garamond, 2009.

BELLAMY FOSTER, J. Marx y la fractura en el metabolismo universal de la naturaleza. Revista Herramienta Web, (15), 2014. Recuperado a partir de http://www.herramienta.com.ar/herramienta-web-15/marx-y-la-fractura-en-elmetabolismo-universal-de-la-naturaleza

BOLADOS GARCÍA, P., \& SÁNCHEZ CUEVAS, A. Una ecología política feminista en construcción: El caso de las "Mujeres de zonas de sacrificio en resistencia". Revista Psicoperspectivas. Individuo y Sociedad, 16 (2), 33-42, 2017.

CARRASCO BENGOA, C. Economía, trabajos y sostenibilidad de la vida. En Reas Euskadi (Ed.), Sostenibilidad de la Vida. Aportaciones desde la Economía Solidaria, Feminista y Ecológica (pp. 27-42). Bilbao: Reas Euskadi, 2012.

CARRASCO BENGOA, C. Con voz propia. La economía feminista como apuesta teórica y política. Madrid: La oveja roja, 2014.

CIELO, C., \& VEGA, C. (2015). Reproducción, mujeres y comunes. Leer a Silvia Federici desde el Ecuador actual. Nueva Sociedad, (256), 132-144, 2015. 
COLECTIVO DE GEOGRAFÍA CRÍTICA DEL ECUADOR. Geografiando para la resistencia. Los feminismos como práctica espacial. Cartilla 3. Quito, 2018.

DALLA COSTA, M. Las mujeres y la subversión de la comunidad. En S. James \& M. Dalla Costa (Eds.), El poder de la mujer y la subversión de la comunidad. México: Siglo XXI, 1972.

FALQUET, J. Hacia un analisis feminista y dialectico de la globalizacion neoliberal: el peso del complejo militaro-industrial sobre las «mujeres globales». Revista Internacional de Pensamiento Político, (9), 2014.

FEDERICI, S. Calibán y la bruja. Mujeres, cuerpo y acumulación originaria. Buenos Aires: Tinta Limón Ediciones, 2010.

FEDERICI, S. Revolución en punto cero. Trabajo doméstico, reproducción y luchas feministas. Madrid: Traficantes de Sueños, 2013.

FEDERICI, S. El patriarcado del salario. Críticas feministas al marxismo. Madrid: Traficantes de Sueños, 2018.

FÉLIZ, M. Renta extraordinaria e industrialización en el neodesarrollismo. Límites y alternativas. Argentina, 2003-2012. Revista Economia Ensaio, 29(1), 7-24, 2014.

FÉLIZ, M. Limits and barriers of neodevelopmentalism: Lessons from Argentina's experience, 2003-2011. Review of Radical Political Economics, 47(1), 70-89, 2015a. https://doi.org/10.1177/0486613413518729

FÉLIZ, M. ¿Neodesarrollismo en retirada? Economía política de un proyecto de desarrollo. Argentina 2002-2015. Revista Despierta, 2(2), 55-82, 2015b.

FÉLIZ, M. ¿Qué hacer... con el desarrollo? Neodesarrollismos, buenvivir y alternativas populares. Sociedad y Economía, (28), 29-49, 2015c.

FÉLIZ, M. Neodevelopmentalist and dependent Argentina in the 21st century: analyzing peripheral capitalist development through the work of Ruy Mauro Marini. Latin American Perspectives. First Published October 21, 2019). https://doi.org/10.1177/2F0094582X18806588 
FÉLIZ, M., \& DÍAZ LOZANO, J. A. Trabajo, territorio y cuerpos en clave neodesarrollista. Argentina, 2002-2016. Revista Perfiles Latinoamericanos, 52, 2018.

GAGO, V., \& MEZZADRA, S. Para una crítica de las operaciones extractivas del capital. Patrón de acumulación y luchas sociales en el tiempo de la financiarización. Nueva Sociedad, (255), 38-52, 2015.

GARCÍA TORRES, M. Una lectura sobre la articulación de Mujeres Amazónicas frente al extractivismo petrolero en la provincia de Pastaza, Ecuador (Tesis para obtener el título de maestría en Estudios Socioambientales). Facultad Latinoamericana de Ciencias Sociales, FLACSO Ecuador, Quito, 2017.

GEBARA, I. Intuiciones ecofeministas: ensayo para repensar el conocimiento y la religión. Madrid: Trotta, 2000.

HARTMANN, H. El matrimonio mal avenido. Hacia una unión más progresiva entre entre marxismo y feminismo. Zona Abierta, (24), 85-113, 1980.

HOCHSCHILD, A. R. La mercantilización de la vida íntima. Apuntes de la casa y el trabajo. Madrid: Katz Editores, 2008.

HOLLOWAY, J. Crisis, fetichismo y composición de clase. Cuadernos del Sur, 14, 87-112, 1992.

LINEBAUGH, P., \& REDIKER, M. The Many-Headed Hydra: Sailors, Slaves, Commoners, and the Hidden History of the Revolutionary Atlantic, Verso Books.(1ra digital). Boston: Beacon Press, 2002.

LUJÁN, J. Entrevista realizada a Jenny Luján. Programa radial de la Cátedra Libre Virginia Bolten [Radionauta FM 106.3], 14 junio 2017. Recuperado a partir de https://radionauta.com.ar/2017/06/14/que-los-gobiernos-firmen-lo-quequieran-aca-la-mineria-no-entra/

LUXEMBURG, R. La acumulación de capital. (2018). Recuperado a partir de http:/grupgerminal.org/?q=system/files/LA+ACUMULACIÓN+DEL+CAPITAL.pd $f$ 
MACHADO ARÁOZ, H. En las encrucijadas del extractivismo: gobiernos progresistas vs. Movimientos del Buen Vivir y el (eco)socialismo del Siglo XXI. Revista Herramienta, (53), 2013. Recuperado a partir de http://www.herramienta.com.ar/revista-herramienta-n-53/en-las-encrucijadasdel-extractivismo-gobiernos-progresistas-vs-movimientos

MARINI, R. M. América Latina, dependencia y globalización / Ruy Mauro Marini. (C. E. Martins, Ed.). Buenos Aires: Siglo XXI Editores / CLACSO, 2015a. Recuperado a partir de https://www.clacso.org.ar/antologias/detalle.php?id_libro=1034

MARINI, R. M. Dialéctica de la dependencia (1973). En C. E. Martins (Ed.), América Latina, dependencia y globalización / Ruy Mauro Marini (pp. 107150). Buenos Aires: Siglo XXI Editores / CLACSO, 2015b.

MARTÍNEZ ALIER, J. Ecología política del extractivismo y justicia socio$\begin{array}{llll}\text { ambiental. } & \text { Interdisciplina, } & \text { 3(7), 57-73, } 2015 .\end{array}$ http://dx.doi.org/10.22201/ceiich.24485705e.2015.7.52384

MARTÍNEZ ALLIER, J. El ecologismo de los pobres. Conflictos ambientales y lenguajes de valoración. Madrid: Icaria, 2004.

MARX, C. El capital. Crítica de la economía política. Tomo I/Vol.3. Libro primero. El proceso de producción del capital (16va ed., Vol. 3). México: Siglo XXI Editores, 1995.

MELÓN, D. (Ed.). La patria sojera : el modelo agrosojero en el Cono Sur (1ra ed.). Buenos Aires: Editorial, 2014. El Colectivo. Recuperado a partir de http://cdn.biodiversidadla.org/content/download/114709/850715/version/1/file/La + Patria+Sojera.pdf

MÉSZÁROS, I. Beyond capital: toward a theory of transition. London : New York: Merlin Press ; Monthly Review Press, 1995.

MIES, M., \& SHIVA, V. (Eds.). Ecofeminismo. Teoría, crítica y perspectivas. Barcelona: Icaria editorial, 1997. 
MOORE, J Entrevista a Jason Moore: Del Capitaloceno a una nueva política ontológica [Ecología Política]. Junio 2017. Recuperado a partir de http://www.ecologiapolitica.info/?p=9795

O'CONNOR, J. Causas naturales. Ensayos de marxismo ecológico (1 ra ed.). México: Siglo XXI Editores, 2001.

PEREDO BELTRÁN, ELIZABETH. Ecofeminismos. En Solón, Pablos (comp) Systemic Alternatives Pp 101-130, 2017. La Paz: Bolivia. Versión en español, recuperada de:https://systemicalternatives.org/2017/03/23/ecofeminismo/

PÉREZ OROZCO, A. Subversión feminista de la economía. Aportes para un debate sobre el conflicto capital-vida. Madrid: Traficantes de Sueños, 2014.

PÉREZ ROIG, D., SCANDIZZO, H., \& DI RISIO, D. Vaca Muerta. Construcción de una estrategia Políticas públicas ambiguas, empresas estatales corporatizadas y diversificación productiva a medida. Buenos Aires: Ediciones del Jinete Insomne, 2016.

PULEO, A. Del ecofeminismo clásico al deconstructivo: principales corrientes de un pensamiento poco conocido. En C. Amorós \& A. De Miguel (Eds.), Historia de la teoría feminista. De la llustración a la globalización (pp. 121152). Madrid: Minerva, 2005.

PULEO, ALICIA Ecofeminismo para otro mundo posible. Madrid: Ediciones Cátedra, 2011.

SABBATELLA, I. Capital y Naturaleza: Crisis, desigualdad y conflictos ecológicos. Presentado en II Jornadas de Economía Política, Malvinas Argentinas: UNGS, 2008.

SCANDIZZO, H. El negocio de la trata en la ruta del petróleo. En C. Korol (Ed.), Resistencias populares a la recolonización del continente. Segunda Parte (1ra ed.). Buenos Aires: Centro de Investigación y Formación de los Movimientos Sociales Latinoamericanos: América Libre: Rosa-Luxemburg Stiftung, 2010. Recuperado a partir de 
http://libros.metabiblioteca.org/bitstream/001/537/1/Resistencias\%20populares \%20a\%20la\%20recolonización\%20del\%20continente.pdf

SCANDIZZO, H. La tentación de Esquisto. Buenos Aires: Ediciones del Jinete Insomne, 2016. Recuperado a partir de http://www.opsur.org.ar/blog/wpcontent/uploads/2017/02/2016-La-Tentación-de-Esquisto.pdf

SEGATO, R. L. La escritura en el cuerpo de las mujeres asesinadas en Ciudad Juárez. Buenos Aires: Tinta Limón Ediciones, 2013. Recuperado a partir de http://tintalimon.com.ar/libro/LA-ESCRITURA-EN-EL-CUERPO-DELAS-MUJERES-ASESINADAS-EN-CIUDAD-JUREZ

SILVA SANTISTEBAN, R. Mujeres y conflictos ecoterritoriales. Impactos, estrategias, resistencias. (1ra ed.). Lima: Entrepueblos / AIETI / Demus Estudio para la Defensa de los Derechos de la Mujer / CMP Flora Tristán / Coordinadora Nacional de Derechos Humanos, 2017.

SVAMPA, M., \&VIALE, E. Maldesarrollo. La Argentina del extractivismo y el despojo (1ra ed.). Madrid: Katz Editores, 2014.

TOMMASINO, H., FOLADORI, G., \& TAKS, J. La crisis ambiental contemporánea. En G. Foladori \& N. Pierri (Eds.), ¿Sustentabilidad? Desacuerdos sobre el desarrollo sustentable (pp. 9-26). México: Miguel Ángel Porrúa / Universidad Autónoma de Zacatecas, 2005. Recuperado a partir de https://diversidadlocal.files.wordpress.com/2012/09/desacuerdossobre-el-desarrollo-sustentable.pdf

VALDÉZ GUTIERREZ, G. El sistema de dominación múltiple. Hacia un nuevo paradigma emancipatorio (Tesis de doctorado). Universidad de La Habana, La Habana - Cuba, 2002.

VEGA CANTOR, R. El imperialismo ecológico. El interminable saqueo de la naturaleza y de los parias del sur del mundo. Herramienta, (31), 2006. Recuperado a partir de http://www.herramienta.com.ar/revista-herramienta-n31/el-imperialismo-ecologico-el-interminable-saqueo-de-la-naturaleza-y-de-los-

VEGA SOLÍS, C. Culturas del cuidado en transición. Espacios, sujetos e imaginarios en una sociedad de migración. Catalunya: UOC, 2009. 
VIVEROS VIGOYA, M. La interseccionalidad: una aproximación situada a la dominación. Debate $\quad$ Feminista, 52, 2016. https://doi.org/10.1016/j.df.2016.09.005

ZIBECHI, R. La sociedad extractiva, 12 mayo 2017. Recuperado 5 de abril de 2018, a partir de https://www.lavaca.org/deci-mu/la-sociedad-extractiva/ 